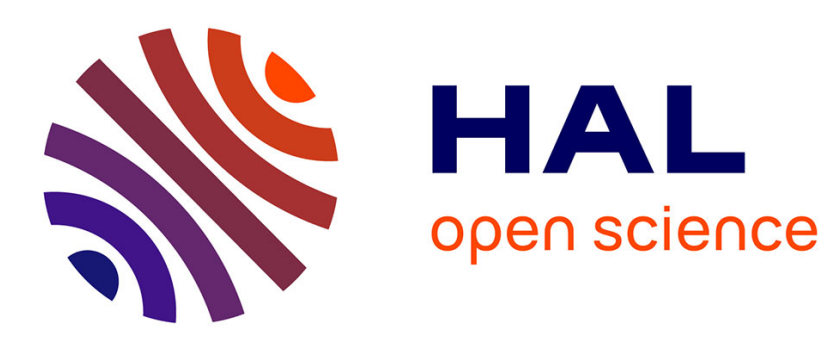

\title{
Comment et pourquoi mesurer l'humidité des sols
}

\author{
Yann H. Kerr
}

\section{To cite this version:}

Yann H. Kerr. Comment et pourquoi mesurer l'humidité des sols. La Houille Blanche - Revue internationale de l'eau, 2010, 2, pp.1-4. 10.1051/lhb:2010024 . ird-00495361

\section{HAL Id: ird-00495361 https://hal.ird.fr/ird-00495361}

Submitted on 25 Jun 2010

HAL is a multi-disciplinary open access archive for the deposit and dissemination of scientific research documents, whether they are published or not. The documents may come from teaching and research institutions in France or abroad, or from public or private research centers.
L'archive ouverte pluridisciplinaire HAL, est destinée au dépôt et à la diffusion de documents scientifiques de niveau recherche, publiés ou non, émanant des établissements d'enseignement et de recherche français ou étrangers, des laboratoires publics ou privés. 


\title{
Comment et pourquoi mesurer l'humidité des sols
}

\author{
How and why measure Soil moisture? \\ Y.H. KERR, \\ CESBIO, Toulouse
}

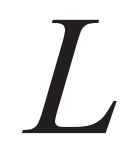

'humidité superficielle a toujours été une variable de surface très recherchée, mais son obtention de façon mondiale c'est toujours avérée une gageure. La quête pour cette humidité a commencé à trouver une solution avec l'avènement des mesures de l'espace (télédétection). Cependant toutes les techniques tentées à ce jour ont trouvées leurs limitations, et ce n'est qu'avec l'apparition de nouvelles approches (en télédétection hyperfréquences passives) que de véritables solutions commencent à pouvoir être envisagées. Le but de cette présentation est de donner un aperçu des techniques existantes, de leurs avantages et inconvénients respectifs ainsi que des possibilités futures a moyen ou court terme avec des missions prévues.

$S$ oil moisture has always been a most required surface variable, but its retrieval in a global fashion has always proved very difficult. The quest for the soil moisture started to find solutions when remotely sensed data became available. The goal of this presentation is to try to give an overview of existing all over the available spectrum, asses advantages and drawbacks with respect to varying end uses so as to identify the different possibilities currently available as well as the potential ways forward. The first goal of this keynote is to endeavour to give a view of the history and the current state of the art of "global" soil moisture retrievals. The second goal is to provide a feeling of what could be the future evolution required to obtain, from space, accurate, adequate, and useful information on soil moisture.

\section{I 口 INTRODUCTION}

Soil moisture is certainly an important life sustaining element. The first "use" of soil moisture, is to enable vegetation growth. Actually, water stored in the soil, plays many other roles. It controls the partitioning of rainfall into runoff and infiltration, and efficient infiltration usually means replenishing the water table, while runoff may mean both exportation of valuable water to other areas and degradation of top soil through erosion. Also, when saturated, soil may transform heavy rainfalls into floods. Consequently, Soil moisture is a key variable for improving the forecasting skills of run off models which aim at flood risk prediction and / or water resources management.

Surface soil moisture is also important as it controls soil evaporation and vegetation transpiration and thus the heat and mass transfers between the earth and the atmosphere. It is consequently very useful in weather forecast models, through global circulation models.

Finally continuous monitoring of soil moisture on a large scale and over long periods of time gives a significant insight on climate changes. But soil moisture is a very vague term and it is important to define it. The most common understanding of the term is the total amount of water in the unsaturated zone. For practical reasons it is often separated into two components, surface soil moisture corresponding to the first centimetres ( $5 \mathrm{~cm}$ in general), and the root zone soil moisture or second reservoir. Soil moisture is usually expressed in gravimetric units $(\mathrm{g} / \mathrm{cm} 3)$ or volumetric units $(\mathrm{m} 3 / \mathrm{m} 3)$. Sometimes it is expressed in function of the wilting point and the field capacity. The two latter metrics are soil type dependent.

\section{II — WHAT EXISTS}

To achieve the goals mentioned above, it is necessary to have access to soil moisture estimates. Punctually in space and time this is relatively easy with gravimetric sampling.

However, to have measurements representative of a larger area (such as a field), the procedure is already somewhat complex as it involves a dedicated sampling strategy. Moreover, as these measurements are time consuming, regional and, even more so, global coverage is out of question. Provided one uses automatic probes (resistive, capacitive, time domain reflectometry etc ) it is possible to achieve larger coverages and continuous measurements but these approaches can only be confined to well equipped and manned sites, as they require care and maintenance. Finally these systems carry their own problems and inaccuracies. So global monitoring of soil moisture can only rely on remote sensing from space approaches. 


\section{II.1 REMOTELY SENSED SOIL MOISTURE, THE MAIN APPROACHES}

A large number of remote sensing approaches have been tested. For surface soil moisture, the first ones were based on short wave measurements and on the fact that soils get darker when wet. Obviously, due to atmospheric effects and potential cloud cover, as well as vegetation cover masking effects, this approach is bound to fail in most cases. A more promising feature is linked to latent heat effects. Wet soils have a higher thermal inertia and are "cooler" than dry soils. These properties led to various trials (thermal inertia monitoring, rate of heating in the morning, surface temperature amplitude etc ) to assess soil moisture indirectly. All those approaches proved to be somewhat disappointing due to factors inherent to optical remote sensing (atmospheric effects, cloud masking, vegetation cover opacity) as well as to the fact that thermal infrared i) probes the very skin of soils and ii) this layer and is dominated by the exchanges with the atmosphere. Consequently to infer soil moisture from such measurements one needs to know exactly the forcings (wind, for instance, will change drastically the apparent temperature of a wet soil).

As microwave systems measure the dielectric constant of soils which is directly related to the water content, research has quickly focussed its efforts on assessing soil moisture with Radars, scatterometers or radiometers. These systems offer, when operated at low frequency, the added advantage of being all weather (measurements are not much affected by the atmosphere and clouds) and able to penetrate vegetation. They can operate at night. Finally, in an attempt to be exhaustive, a new approach, relying on measurements of the gravity field from space, is said to indicate changes the total column of water with a spatial resolution of $500 \mathrm{~km}$ or more. The first results certainly show a signal but its relationship with water storage has yet to be validated and explicited. (GCM) (Han et al. 2005).

\section{II.2 MICROWAVE AS A TOOL FOR SOIL MOISTURE MONITORING : CURRENT STATUS}

The most popular approach relies on the use Synthetic Aperture Radars (SAR). These systems, in use since 1977 with SEASAT, offer all weather measurements with a fine spatial resolution (tens of meters). Operationally they however suffer - as most high resolution systems - from a rather low temporal sampling (35 days for the European Remote Sensing satellite (ERS) for instance) which is not really compatible with hydrologic requirements or weather forecast models. But the most adverse characteristic of SAR is the coherent nature of the signal itself and the interactions with the scattering medium. SAR images are affected by speckle and by the scattering at the surface. The scattering can be due to the vegetation cover (distribution of water in the canopy) or the soil's surface (surface scattering when wet, and volume scattering). The direct consequence of these perturbations is a signal at least as much sensitive to surface roughness as to moisture itself (see also (Wigneron et al. 1999)), not mentioning vegetation. Obviously these effects are frequency dependent. All these inherent difficul- ties might explain that, though several SAR flew since 1977, neither were they used in a standard and routine fashion, nor any real soil absolute moisture mapping was really done. To avoid the roughness and vegetation perturbations, an approach relying on change detection, hence relative, has been used with relative success (Moran et al. 2002). However, temporal coverage is still often an issue. The use of scatterometers offers an interesting trade off. The spatial resolution is much coarser (tens of kilometres) but with a much wider swath allowing reasonably frequent coverage (every 4 to 6 days on average). It offers also the added advantage of being somewhat much less subject to speckle (averaging). Consequently, several authors produce routinely soil wetness maps of many areas of the world with scatterometers.

The effect of vegetation is however still significant and corresponds actually to most of the signal as the available frequencies currently available are C-band on (ERS-1) and higher. So the most interesting results were obtained over arid and semi arid regions where anyway vegetation and soil moisture are very highly correlated. The influence of surface roughness is also significant and it is best dealt with by using change detection.

The last possibility in the microwave domain is to use radiometers. The technique is old and well mastered as many sensors and notably sounders rely on passive microwaves. To infer soil moisture, these systems are bound to offer the best compromise if used at low frequency, as demonstrated in the early seventies with the very short SKYLAB mission. However, to be efficient, one needs to work in a protected frequency band to avoid unwanted man made emissions and Radio Frequency Interferences (RFI) and to be sensitive to soil moisture while atmosphere is transparent and vegetation plays a limited role. At L band the emissivity may vary from almost 0.5 for a very wet soil to almost 1 for a very dry one giving a range of $80-100 \mathrm{~K}$ for an instrument sensitivity usually of the order of $1 \mathrm{~K}$. As the signal is not coherent, surface roughness and vegetation structure play a reduced role when compared to active system. So one may wonder why L-band radiometry was not use extensively before when it had been proved to be most efficient during ground and airborne measurements (Schmugge et al. 1988). This is due to an inherent limitation : the spatial resolution is proportional to the antenna diameter and inversely proportional to the wavelength. At $21 \mathrm{~cm}$, to achieve a $40 \mathrm{~km}$ resolution from an altitude of $750 \mathrm{~km}$ requires and antenna of about $8 \mathrm{~m}$ in diameter which is a very significant technical challenge. So the research was performed with higher frequency systems as available on the Scanning Multichannel Microwave Radiometer -SMMR- (6.6 GHz) (Kerr and Njoku 1990), the Special sensor Microwave Imager -SSM/I- (19 GHz) and now the Advanced Microwave Scanning Radiometer -AMSR-E- (6.8 GHz) (Njoku and Li 1999). Even though the frequency is not adapted, good results were obtained with SMMR (in spite of a very poor resolution due to important side lobes) and now AMSR-E (Njoku and Li 1999). The limitations are mainly linked to the fact that the vegetation becomes rapidly opaque, the frequency is not protected and thus bound to be polluted by RFIs, and the single angular measurement makes it difficult - in several cases - to separate vegetation and soil contributions to the signal. 


\section{III — THE STEP FORWARD}

Considering the necessity to make L band measurements, several approaches have been tested to overcome the antenna size issue. The first was initiated in the early $90 \mathrm{~s}$ with the idea to apply radio astronomy techniques (very large arrays and very large baseline interferometers) to Earth remote sensing. The one-dimensional concept, Electronically Scanned Thinned Array Radiometer (ESTAR) was implemented as an aircraft version and proved to fulfil the requirements (Le Vine et al. 1994). It is a system, deployable in space as a sort of large rake and offering - at the cost of a reduced sensitivity an acceptable spatial resolution. In parallel another approach, using inflatable (or umbrella-like deploying technology) was studied at the Jet Propulsion Laboratory (JPL). Both concepts were proposed on several occasions to space agencies without success. The concepts appeared to be complex to deploy and to run, or to offer too limited measurements (single angle and frequency). By 1991 a small group started to work for ESA on the development of a similar instrument but working in two dimensions (Goutoule et al. 1996). The concept was named Microwave Imaging Radiometer with Aperture Synthesis (MIRAS) and an airborne prototype was made and operated (Bayle et al. 2002). From then on the concept evolved into a more tailored instrument which was proposed to the European Space Agency (ESA) (Kerr 1998) in the framework of the Earth Explorer Opportunity mission under the name of Soil Moisture and Ocean Salinity (SMOS) mission. The mission was selected and is now underway. It is an ESA lead project with contribution from France and Spain. SMOS is scheduled for a launch in 2008 and is thus for the very near future (Kerr et al. 2001). Similarly, a mission proposal was submitted to NASA, the Hydrospheric mission (Hydros) (Entekhabi et al. 2004). This mission relied on a deployable and rotating antenna related to both a radiometer and a scatterometer. SMOS is a $\mathrm{Y}$ shaped instrument consisting of 69 elementary antennas regularly spaced along the arms providing at each integration step a full image (about $1000 \times 1200 \mathrm{~km}$ ) at either 2 polarisations or full polarisation of the earth's surface (Kerr et al. 2001). The average ground resolution is $43 \mathrm{~km}$ and the globe is fully imaged twice (ascending and descending orbits) every 3 days at 6 am and $6 \mathrm{pm}$ local solar time. As the satellite travels on the orbit, any point of the surface is imaged at several angles, giving the angular signature of the pixel. The beauty of the concept is thus that a reasonable spatial resolution is obtained at the cost of a reduced sensitivity. Moreover, the pixels are viewed frequently at different angles and polarisations. The angular information is then used to separate the different contributions (soil - vegetation) to the signal (Wigneron et al. 2000).

\section{IV — ROOT ZONE SOIL MOISTURE}

The big caveat of the remotely sensed soil moisture is that the direct measurement only concerns the surface layer. For instance, at $\mathrm{X}$ band a few $\mathrm{mm}$, at $\mathrm{L}$ band $4-5 \mathrm{~cm}$ are probed on average (depending on soil characteristics and condition). It is necessary however, for several applications, to know the available water in the unsaturated zone. Only one direct approach can currently be considered, i.e., to use even lower frequencies (wavelengths of several meters) so as to reach deeper layers. This leads to large problems in terms of spatial resolution (few hundred $\mathrm{km}$ ) a swell as of ionospheric effects. So this option is not feasible now. The indirect approaches could be, either to use gravity change approaches (if really validated and provided very coarse resolutions -hundreds of $\mathrm{km}$-are acceptable) ; or to rely on assimilation techniques, i.e., using models to infer- from regular surface measurements and forcing conditions - what the root zone soil moisture is. The approach has been validated both using simulations and using ground data. The real limitations are linked to the models ability and input data quality.

\section{$V \square$ EXPRESSION OF NEEDS}

Obviously apart from the fact that the unsaturated zone is only partly probed there are some requirements are not fully fulfilled. The main one is the spatial resolution. Some needs, notably in hydrology, can only be resolved by having a better spatial resolution but still with a high temporal sampling. From space, this is not straightforward, but the most promising is probably to use external information to redistribute the area average moisture within the pixel : the so called dis-aggregation. Several studies recently proved the feasibility of the approach with SMOS data (Pellenq et al. 2003 ; Merlin et al. 2006) and now the real life validation has only to be performed.

\section{D CAVEATS}

It is not intended to say here that everything is resolved and fine. There are still a number of outstanding issues which will require attention before an accurate and global soil moisture product is routinely delivered. Some, such as RFI can be a general issue, especially if protection is reduced in the future, which is a concern. The specific issues identified are currently being tackled and several references in the literature identify them but, obviously, as long as the actual data (SMOS or any other) are not available, definitive conclusions and/or solutions will not be available and some unexpected issues might arise. Currently, the following issues are well identified. The most stringent is the pixel heterogeneity with components which may have very significant differences in behaviour. The presence of free water within the pixel for instance has to be every accurately known (better than $2 \%$ ) to reach the overall accuracy of $4 \%$ vol. in soil moisture. And water bodies can be variable as a function of season or weather. Vegetation is not totally opaque at L band, and when the integrated water content is above $4-5 \mathrm{~kg} / \mathrm{m} 2$, soil moisture retrievals will be difficult and approximate. Hence, forested canopies will impact the signal. It may be noted at this level that recent studies showed that the main contributor at $\mathrm{L}$ band for forest was the branch which does not evolve so rapidly (Ferrazzoli et al. 2002). Litter on the ground may behave as black body, masking strongly the soil's signal. During rain events, water interception by the canopy might artificially increase the apparent vegetation water content. Topography will induce an altered 
angular behaviour ; snow and frozen soils will induce different signals which, if not accounted for, will produce wrong estimates. Urban areas, rocks, are not fully assessed in terms of emissivity. Finally, and generally speaking, good retrieval will require some a priori knowledge of the surface cover and state and the quality of the retrievals will be linked to the quality of the input data (Kerr et al. 2005). It must also be noted that systems like SMOS will bring inherent specificities and complexities such as image reconstruction (Anterrieu 2004) which is still a challenging point.

\section{VII —CONCLUSION AND PERSPECTIVES}

After many unsuccessful attempts, a real soil moisture mission is now under way. Until launched and commissioned, the concept has to be proved but the elements available can make one very confident to such an extent that an operational SMOS follow-on is currently being studied. Nevertheless, SMOS, if answering some questions still does not fulfil all the needs and ways forward must be sought. The most important is probably to improve the spatial resolution and there the SMOS concept is close to an optimum, as increasing the arm's length will improve the spatial resolution but degrade significantly the sensitivity, to the point that it would not be useful anymore. So other techniques, such as dis-aggregation, will have to be found. To be more efficient a SMOS-like instrument might gain from either being multifrequency or having a coupled active system. It is expected to test these solutions using existing sensors (Advanced SCATterometer (ASCAT) and AMSR-E) when SMOS is operating. Another approach to improve spatial resolution could be to use even larger antennas, pending it is possible to deploy them efficiently in space. In that case, to resolve the ambiguities, it will probably be necessary to improve the system by adding other frequencies while keeping the active source. This might lead to addressing also the cryosphere, another key element in the global water and energy budget of the planet. It was stated in the SMOS proposal that the concept, though challenging, would open a new field with new measurements made with a new type of sensors, paving the way for operational monitoring of water in soils. With the inception of the SMOS mission, this step is taken, opening a whole avenue of scientific challenges, and making the long awaited tool for water resources and water cycle monitoring a closer possibility.

\section{VIII — REFERENCES}

[1] E. ANTERrieu (2004) - A resolving matrix approach for Synthetic Aperture Imaging Radiometers. IEEE Trans Geosci. Remote Sens. 42(8) 1649-1656

[2] F. Bayle, J.-P. Wigneron, Y. H. Kerr, P. Waldteufel, E. Anterrieu, J.-C. Orlhac, A. Chanzy, O. Marloie, M. Bernardini, S. Sobjaerg, J.-C. Calvet, J.-M. Goutoule, N. SKOU (2002) - Two-dimensional synthetic aperture images over a land surface scene. IEEE Trans. Geosci. Rem. Sens. 40(3) $710-714$

[3] D. Entekhabi, E. G. Njoku, P. Houser, M. Spencer, T. Doiron, Y. Kim, J. Smith, R. Girard, S. Belair, W. Crow,
T. J. Jackson, Y. H. Kerr, J. S. Kimball, R. Koster, K.C. Mcdonald, P. E. O'Neill, T. Pultz, S. W. Running, J. Shi, E. WoOD, J. VAN ZYL (2004) - The Hydrosphere State (Hydros) Satellite mission : an Earth system pathfinder for global mapping of soil moisture and land freeze/thaw. IEEE Trans. Geosc. Remote Sens. 42(10) 2184-2195

[4] P. Ferrazzoli, L. Guerriero, J. P. Wigneron (2002) Simulating L-band emission of forests in view of future satellite applications. IEEE Trans. Geosci. Remote Sens. 40(12) 2692-2708

[5] J. M. Goutoule, E. Anterrieu, Y. H. Kerr, A. Lannes, N. SKOU (1996) - MIRAS Microwave radiometry critical technical development. TOULOUSE, MMS.

[6] S.-C. Han, C. K. Shum, C. Jekeli, D. Alsdorf (2005) Improved estimation of terrestrial water storage changes from GRACE. (doi 10.1029/2005GL022382 : L07302). Geophys. Res. Lett. 32

[7] Y. Kerr, P. Waldteufel, P. Richaume, I. Davenport, P. FERRAZZOLI, J.-P. Wigneron (2005) - SMOS level 2 processor Soil moisture ATBD. Toulouse, SM-ESL (CBSA). 110

[8] Y. H. Kerr, E. G. NJoKu (1990) — A semiempirical model for interpreting microwave emission from semiarid land surfaces as seen from space. IEEE Trans. Geosci. Remote Sens. 28(3) 384-393

[9] Y. H. KERR (1998) - The SMOS Mission : MIRAS on RAMSES. A proposal to the call for Earth Explorer Opportunity Mission. Toulouse (F), CESBIO.

[10] Y. H. Kerr, P. Waldteufel, J.-P. Wigneron, J.-M. Martinuzzi, J. Font, M. Berger (2001) - Soil Moisture Retrieval from Space : The Soil Moisture and Ocean Salinity (SMOS) Mission. IEEE Trans. Geosci. Rem. Sens. 39 (8) 1729-1735

[11] D. M. Le Vine, A. J. Griffis, C. T. Swift, T. J. Jackson (1994) - ESTAR : A Synthetic aperture Microwave Radiometer for Remote Sensing applications. Proc. IEEE. 82 1787-1801

[12] O. Merlin, A. G. Chehbouni, Y. H. Kerr, D. Goodrich (2006) - A downscaling method for distributing surface soil moisture within a microwave pixel : application to Monsoon '90 data. Rem. Sens. Environ. 101 379-389

[13] M. S. Moran, D. C. Hymer, J. Qi, Y. Kerr (2002) Comparison of ERS-2 SAR and Landsat TM imagery for monitoring agricultural crop and soil conditions. Rem. Sens. Environ. 79(2-3) 243-252

[14] E. G. NJoKu, L. Li (1999) - Retrieval of land surface parameters using passive microwave measurements at $6-18 \mathrm{GHz}$. IEEE Trans Geosci.Remote Sens. 37(1) 79-93

[15] J. Pelleng, J. Kalma, G. Boulet, G.-M. Saulnier, S. Wooldridge, Y. Kerr, A. Chehbouni (2003) - A disaggregation scheme for soil moisture based on topography and soil depth. Journal of Hydrology. 276(1-4) 112-127

[16] T. J. Schmugge, J. R. Wang, G. Asrar (1988) - Results from the Push Broom Microwave Radiometer Flights over the Konza Prairie in 1985. IEEE Trans Geosci.Remote Sens. 26(5) 590-597

[17] J.-P. Wigneron, P. Waldteufel, A. Chanzy, J. C. Calvet, Y. KERR (2000) - Two-D microwave interferometer retrieval capabilities of over land surfaces (SMOS Mission). Rem. Sens. Environ. 73(3) 270-282

[18] J. P. Wigneron, P. Ferrazzoli, J. C. Calvet, Y. H. Kerr, P. BertuZzi (1999) - A parametric study on passive and active microwave observations over a soybean crop. IEEE TGARS. 37(6) 2728-2733 